\title{
Surgical Management of Non opposition Deep Avulsion Wound by Left Iliac Ostectomy in a Cattle
}

\author{
S. Preethi ${ }^{1^{*}}$ and P. Rajaguru ${ }^{2}$ \\ ${ }^{1}$ Veterinary Assistant Surgeon, Veterinary Dispensary, Allapuram, Vellore, Tamil Nadu, India \\ ${ }^{2}$ Veterinary Dispensary, Singarapettai, Krishnagiri Tamil Nadu, India \\ *Corresponding author
}

\begin{abstract}
A B S T R A C T

\begin{tabular}{|l|}
\hline Ke y w o r d s \\
Iliac Ostectomy, \\
Cattle, Deep \\
Avulsion Wound \\
\hline Article Info \\
\hline $\begin{array}{l}\text { Accepted: } \\
\text { 22 June } 2020 \\
\text { Available Online: } \\
\text { 10 July } 2020\end{array}$ \\
\hline
\end{tabular}

A five year old crossbred Jersey cow weighing about $300 \mathrm{~kg}$ was presented with the history of deep avulsion wound on the left side of hip region occurred due to animal hit on the steel thatched roof. Clinical examination revealed deep avulsion wound involving skin and underlying muscles of the left hip region with non opposing irregular edges due to exposure of left wing of ilium bone and loses of skin. The avulsion wound was thoroughly lavaged with $0.1 \%$ chlorhexidine solution and the hair around the wound was shaved and prepared aseptically for surgical opposition. Ostectomy of portion of left wing of ilium bone was performed to oppose the wound edges under high epidural anaesthesia and local infiltration using 2\% lignocaine hydrochloride. Than the wound edges were debrided and apposed with sterile silk by simple interrupted suture pattern. Postoperatively the animal was administered with broad spectrum antibiotic and anti-inflammatory drugs for seven days with regular wound lavaging and dressing. The Cutaneous sutures were removed on tenth post operative day and the animal made uneventful recovery without affecting weight bearing in the particular limb. Ostectomy of ilium bone in a non oppositional wound edges under Lignocaine analgesia were found to be safer, effective and adaptable under field conditions.
\end{abstract}

\section{Introduction}

Lacerated and degloving injuries are common in horses and cattle, because of the small amount of soft tissue covering the bones of the distal extremities. Exposed bone in open wound could delay second intention healing either indirectly and directly. Desiccation of the superficial layers of bone may lead to infectious osteitis and sequestrum formation. The rigid nature of bone indirectly inhibits contraction of granulation tissue and prolongs the inflammatory phase of the wound healing. (Reid Hanson, 2004). Thus the present paper describes the salvage ostectomy of a part of iliac wing as an aid in closing non opposition deep avulsion wound at the left iliac crest in a dairy cattle.

\section{Case History and Physical Examination}

A five year old crossbred Jersey cow weighing about $300 \mathrm{~kg}$ was presented with the history of deep avulsion wound on the left 
lateral side of hip region occurred due to animal hit on the steel thatched roof. Clinical examination revealed deep avulsion wound involving skin and underlying muscles of the left hip region which exposing the left wing of ilium bone and loses of skin. The exposed iliac wing interrupts the opposition of the skin edges and found to very difficult in surgical repair of the wound. So it was decided to perform partial ostectomy of left iliac wing to facilitate the skin closure.

\section{Materials and Methods}

The wound was prepared aseptically by shaving the hair around the wound edges and lavage the wound copiously using $0.1 \%$ chlorhexidine solution, followed by irrigating the wound with povidone iodine diluted in 0.9 per cent normal saline solution. High epidural analgesia with local infiltration was done with 2 per cent Lignocaine hydrochloride. The exposed iliac wing was partially removed with the help of Hacksaw blade soaked in surgical spirit. Than the wound was lavaged once again with sterile saline and povidone iodine. The wound edges were debrided and after iliac ostectomy the wound edges were opposed easily without any excessive tension. Then the wound edges were opposed using sterile silk by simple interrupted suture pattern.

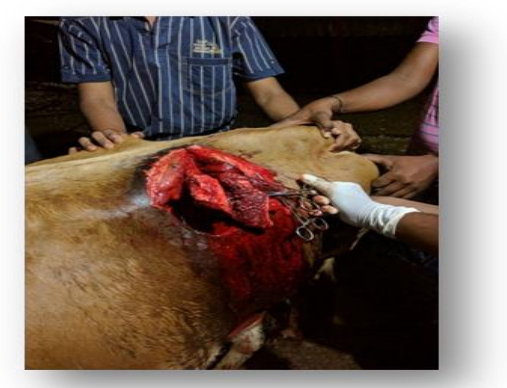

EXPOSED LEFT ILIAC CREST WITH NON OPPOSING WOUND EDGES

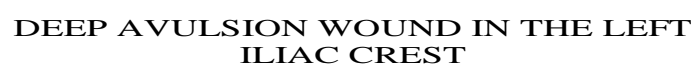

ILIAC CREST

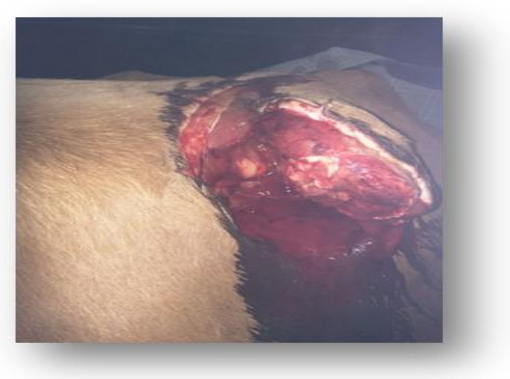

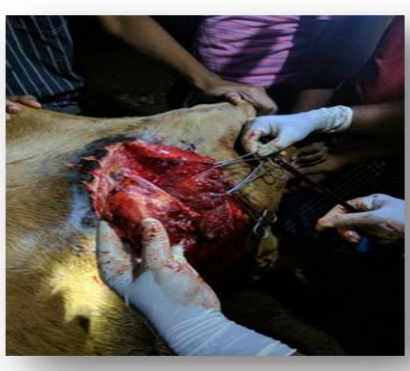

PARTIAL OSTECTOMY OF LEFT ILIAC CREST
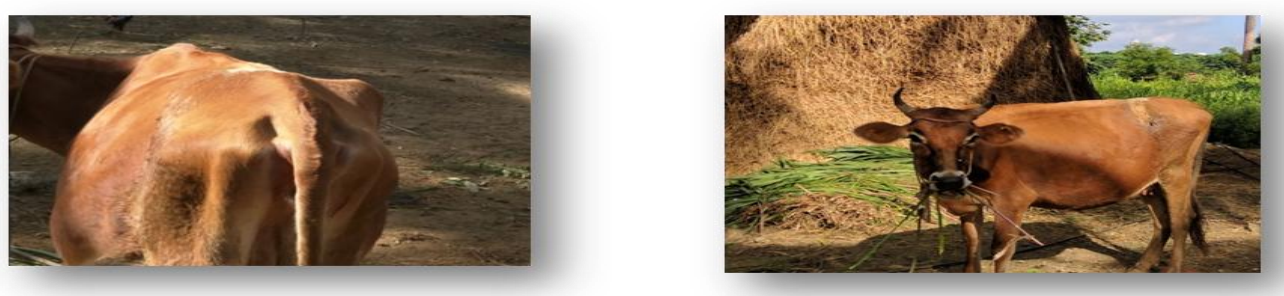

AFTER REMOVAL OF CUTANEOUS SUTURE AT $10^{\mathrm{TH}}$ POST OPERATIVE DAY 


\section{Results and Discussion}

The animal was administered with broad spectrum antibiotics and anti-inflammatories for seven days with regular wound lavaging and dressing with antibiotic. The healing of wound was good without any exudates and wound dehiscence. The animal able to bear weight on the left hind leg without any profound lameness. The Cutaneous sutures were removed on tenth post-operative day and the animal made uneventful recovery.

In conclusion the partial pelvic ostectomy performed in the present case favors union of non opposing avulsion wound without affecting the gait and production of the animal. The animal bears weight in the left hind leg after surgery indicates there is no profound lameness due to ostectomy of the iliac wing. Ostectomy of ilium bone in a non oppositional avulsion wound under Lignocaine analgesia were found to be safer, effective and adaptable under field conditions.

\section{References}

Reid Hanson, R. 2004. Management of Avulsion wounds with exposed bone. Clin. Tech. Equine Pract. 3: 188-203.

\section{How to cite this article:}

Preethi, S. and Rajaguru, P. 2020. Surgical Management of Non opposition Deep Avulsion Wound by Left Iliac Ostectomy in a Cattle Int.J.Curr.Microbiol.App.Sci. 9(07): 3292-3294. doi: https://doi.org/10.20546/ijcmas.2020.907.383 